\title{
PCA3 mRNA to PSA mRNA Ratio Measurement
}

National Cancer Institute

\section{Source}

National Cancer Institute. PCA3 MRNA to PSA MRNA Ratio Measurement. NCI

Thesaurus. Code C132378.

The determination of the ratio of prostate cancer antigen 3 mRNA as compared to the total prostate specific antigen mRNA present in a sample. The measurement may be expressed as a ratio or percentage. 